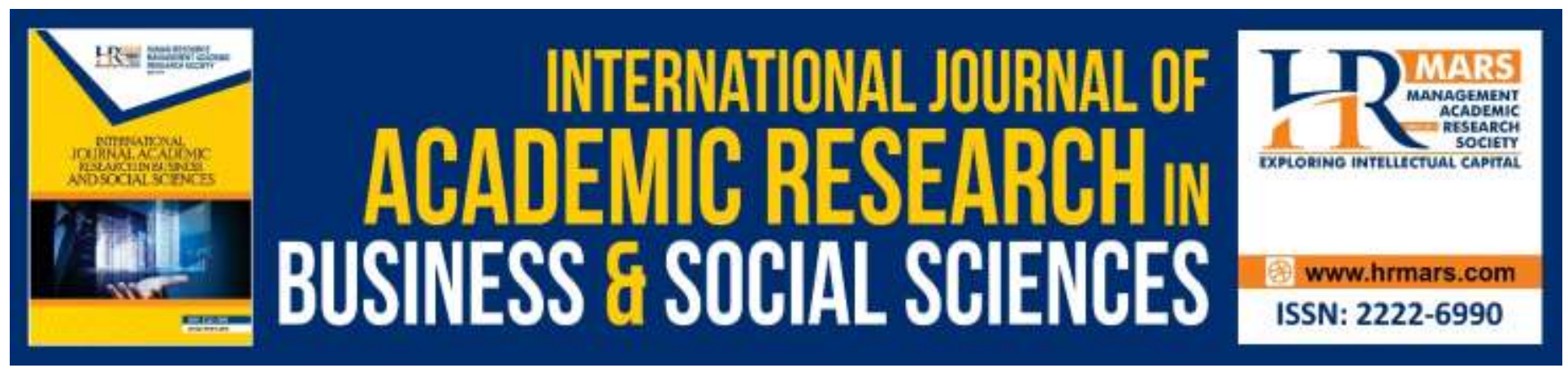

\title{
Comparison Level of Handgrip Strength, Finger Grip Strength and Anthropometric Measurement among Artificial Wall Athletes
}

Siti Nursarah Salehhodin, Borhannudin Abdullah, Hanis Mohd Khalid

To Link this Article: http://dx.doi.org/10.6007/IJARBSS/v9-i11/6566

DOI: 10.6007/IJARBSS/v9-i11/6566

Received: 13 October 2019, Revised: 30 October 2019, Accepted: 13 November 2019

Published Online: 30 November 2019

In-Text Citation: (Salehhodin, Abdullah, \& Khalid, 2019)

To Cite this Article: Salehhodin, S. N., Abdullah, B., Khalid, H. M. (2019). Comparison Level of Handgrip Strength, Finger Grip Strength and Anthropometric Measurement among Artificial Wall Athletes. International Journal of Academic Research in Business and Social Sciences, 9(11), 461-467.

Copyright: (C) 2019 The Author(s)

Published by Human Resource Management Academic Research Society (www.hrmars.com)

This article is published under the Creative Commons Attribution (CC BY 4.0) license. Anyone may reproduce, distribute, translate and create derivative works of this article (for both commercial and non-commercial purposes), subject to full attribution to the original publication and authors. The full terms of this license may be seen at: http://creativecommons.org/licences/by/4.0/legalcode

Vol. 9, No. 11, 2019, Pg. 461 - 467

Full Terms \& Conditions of access and use can be found at http://hrmars.com/index.php/pages/detail/publication-ethics 


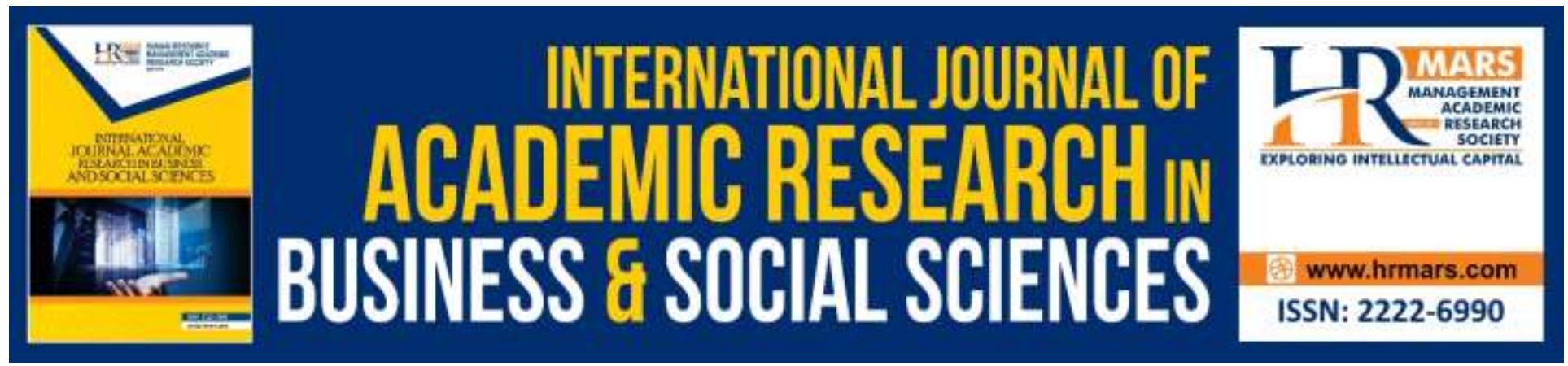

\title{
Comparison Level of Handgrip Strength, Finger Grip Strength and Anthropometric Measurement among Artificial Wall Athletes
}

\author{
Siti Nursarah Salehhodin, Borhannudin Abdullah, \\ Hanis Mohd Khalid \\ Faculty of Educational Studies, Universiti Putra Malaysia
}

\begin{abstract}
Purpose: Sport climbing came about in 1980 as a means of physical and technical training for high performance mountain climbers and it became popular as a competitive and recreational sport activities. The aim of this study were to compare the level of handgrip strength in male athletes between three different categories of climbing (boulder, lead, and speed) during indoor wall climbing competition. Grip strength refers to the ability of the fingers and hand to generate muscle power and force (Chang, Chou, Lin, Lin, \& Wang, 2010). Methodology: Ex-post facto because the characteristics tested on the subjects occur naturally and cannot be manipulated. Participants were 123 males (boulders; 41, lead; 41, speed; 41) whose average age is $22.46 \pm 4$ years. All of them are students of a university in Malaysia. The handgrip strength was measured statically using a hand dynamometer (handgrip). Descriptive statistics was used to compare the different of handgrip strength in three categories. Data from both strength tests were compared for the three categories of climbing using ANOVA. Result: Descriptive data for boulder $(M=102.646 ; S D=14.71)$, lead $(M=92.42 ; S D=15.88)$, and speed $(M=88.13 ; S D=16.43)$ were determined. The findings showed significant differences in handgrip strength score in three categories of climbing $[\mathrm{F}(2,120)=9.26, \mathrm{p}=0.000)]$. Data analysis by using post hoc turkey test showed significance difference between boulder and lead $(p<0.01)$, and boulder and speed $(p=0.000)$. Finding and discussion: Conclusion from this study boulder climber are stronger the lead climbers in handgrip strength.
\end{abstract}

Keywords: Handgrip Strength, Boulder, lead, Speed

\section{Introduction}

Climbing is the sport that has been developing and growing rapidly since the 1980 s either place or the number of climbers climbing artificial walls (PnanaCkova, Reply, Bunc, \& Giles, 2015). It 
getting popular as other sports and wall climbing resemble sports rock climbing or better known as rock climbing. Wall climbing is sport that requires metal and physical strength are high where climbers require movement gymnastics in controlling the movement of the body during climbing wall imitation in a state depends on the surface of the stone (PnanaCkova et al., 2015; Fleming \& Horst, 2010). Handgrip strength involving the hand and arm muscles is a key component of the athletes involved in the sport including artificial wall climbing, judo, weightlifting, basketball, martial arts, and racquet sports. In sport climbing the power gesture refers to ability of fingers and hands to generate strength and muscle power (Bourne, et al., 2011).

Hand grip strength involved on hand and arm muscles and it is a key component of the athletes in sport wall climbing, judo, weightlifting, basketball, martial arts, and racquet sports. Handgrip strength can be one of the factors that can determine the early performance of the test of the hand grip strength includes determining an initial overview of the performance of a climber in a wall climbing competition (Reply, Pecha, Martin, \& Cochrane, 2011; Bourne, Halali, Vanwanseele \& Clarke, 2011; Bohannon, 2008). Data from the handgrip strength test is important to be used as a component in the recovery hand. It can assess the extent and limitations of the initial participants and to provide initial training for the advancement of handgrip strength for climbers, especially the artificial climbing wall.

Sport climbing requires high engagement on the upper body, especially the muscles in the flexor muscles of the fingers. During the climb, isometric arm muscle contractions occur during the climb to the top and to the balance of the body depends especially on the route (Gajewski, \& Jarosiewicz, 2008). Handgrip strength is highly correlated with a variety of other features including anthropometric (weight, height, arm length, etc.). Studies of Ancel et al., (2002) showing the handgrip strength was reported to be higher in the dominant hand, which many on the right hand (Gurer, and Yildiz, 2015; Koley, \& Singh, 2010).

In sport climbing has a number of different categories such as bouldering, speed, and lead (Nick, Dickson, Fryer, \& Ellis, 2011). Bouldering refers to a category that does not require to use any ropes for climbing (Marrison \& Schoffl, 2007). The height is not too high and it's about 4 to 5 meters and falls down when it does not cause any injury to the climber. Use hard mattress and the spotters are important for use as a shelter. Bouldering categories involved a short route which is using more on technical, or called "problem passage" and scoring is calculated by the number of times an attempt to solve the problem in given times (Fanchini, et al., 2013).

Lead climbing is a category that is done at the wall higher than 12 meters and a climbing is longer than the boulder category (Marrison, and Schoffl, 2007). Lead climbing competition is initiated from below and must climb follow the route are available at the time (6-8 minutes) set depending on the organizers. This category is different from bouldering category because climbers need a safety hardness and rope clips on runners in various distance along the route provided (Nick, et al., 2011). Scoring is calculated according to the last hold and longest-held but must hold with a stable.

Speed is one fact that is reflected in the speed category (Ryepko, 2013). This category is usually done either individually or collectively, and the fastest is the winner. This category using the 
safety rope anchored above the climber at the all times and is commonly used by climbers to beginners (Peter, 2004).

\section{Material \& Methods}

This ex post facto research aims to identify the handgrip strength among 123 male climber. The inclusion criteria were climbers are students from the university in Malaysia as research samples. The purposive sampling method are been used and all climber involved in data collecting. Meanwhile, exclusion criteria were climbers who had previous history of any systemic diseases or had musculoskeletal injuries. Subjects were given brief explanations about the study procedures and consent form was obtained prior to their participation in this study. After completing the form, each climber performed the grip strength and finger hangs tests.

\section{Handgrip}

Handgrip dynamometer Takei 5401 Handgrip Dynomometer (Gerodimos, 2012) was used for measuring hand and forearm muscular strength. Data are collected before competition started. The procedures of handgrip test were adapted from Anumula et. al, 2014; Gerodimos, 2012 and by using Takei Handgrip Dynamometer. This tool can measure the strength of the hand grip of 0 to $100 \mathrm{~kg}$ and are widely used in many studies to measure the handgrip strength. The tool of choice for many researchers compatible with a wide range of hands, have good sensitivity and easy to use (Gurer and Yildiz, 2015). Subjects were asked to grip the dynamometer as maximum as they can according to their own comfort. Subjects in the upright position, look straight ahead, hand-held dynamometer tool body with arms straight up in comfortable circumstances. Hand dynamometer are grip as strong as possible without changing the position of the hands (Heyward, 2010). There were dual scale readout of forces which are kilograms $(\mathrm{kg})$ and pounds (lb). However all the average readings were recorded in $\mathrm{kg}$. Tests taken on the dominant hand was done three times within one minute break between each attempt to prevent hand fatigue. There are repeated on the non-dominant hand. The reading of data recorded in accordance with the number of on-screen digital dynamometer tool. The data recorded by the precision of the measuring device is $0.1 \mathrm{~kg}$. The value of the best readings taken and recorded on each hand dominant and non-dominant hand (Valenzuela, et al., 2015; Anumula. Frozen, \& Murthy, 2014; Gerodimos, 2012).

Analyses of Variance (ANOVA) are used to carry out to determine the effect of the intervention on the study group. The analysis will also determine whether there are significant differences in handgrip strength test scores for three different category of climbing (boulder, lead and speed).

\section{Result}

Data collected during the study were analyzed and were interpreted with the help of statistical package program (SPSS 22.0). The handgrips strength scores were analyzed descriptively to get the mean and standard deviation value were to provide an opinion about the data. Based on the analysis, the mean score handgrip strength for boulder was the highest with score of 102.65 $(S D=14.71)$. Mean score lead $92.42(S D=15.88)$ followed by speed at $88.13(S D=16.43)$. 
INTERNATIONAL JOURNAL OF ACADEMIC RESEARCH IN BUSINESS AND SOCIAL SCIENCES

Vol. 9, No. 11, November, 2019, E-ISSN: 2222-6990 @ 2019 HRMARS

Table 1: Descriptive Statistical of Handgrip Strength Score for three different categories of wall climbing

\begin{tabular}{lllll}
\hline Variable & Categories & N & Mean & $\begin{array}{l}\text { Standard } \\
\text { Deviation }\end{array}$ \\
\hline Handgrip Strength & Boulder & 41 & 102.65 & 14.71 \\
& Lead & 41 & 92.42 & 15.88 \\
& Speed & 41 & 88.13 & 116.43 \\
\hline
\end{tabular}

Based on ANOVA analysis that is to compare parameters, there was a significant difference $(p<0.05)$ for handgrip strength score between the three different categories of wall climbing $[F$ $(2,120)=9.26, p=0.000]$ as shown in Table 2 .

Table 2: ANOVA Analysis of Handgrip Strength for three different categories of wall climbing

\begin{tabular}{lllll}
\hline Variance & df & Mean (Square) & F & P Value \\
\hline Between Group & 2 & 2089.50 & 8.48 & $0.001^{*}$ \\
Within Group & 122 & 246.29 & & \\
\hline
\end{tabular}

$* \mathrm{P}<0.01$

Post Hoc comparison showed significant different between three different categories of climbing (Table 3). Post Hoc findings also showed significant between handgrip strength boulder and lead $(p<0.001)$. The scores between boulder and speed also showed significant difference at $p=0.001$. However, when comparing lead and speed categories there was no significant difference $(p>0.005)$.

Table 3: The Different of Post Hoc Test Score between three categories of climbing

\begin{tabular}{llcc}
\hline Comparing Categories & & Differences mean & P Value \\
\hline Boulder & Lead & 9.47 & 0.018 \\
& Speed & 13.75 & 0.001 \\
Lead & Speed & 4.29 & 0.434 \\
\hline
\end{tabular}

${ }^{*} \mathrm{p}<0.01,{ }^{*} \mathrm{p}<0.05$

\section{Discussion}

The aims of this study were to evaluate the handgrip strength for three different categories of wall climbing. The findings have successfully identified significant differences between the three different categories of climbing. Based from pass research, handgrip strength can summarize the evidence to predict important outcomes (Bohannon, 2008) but finding from Michailov (2009), the performance is not stable during different stages. Somehow boulder show the highest score of handgrip strength but it doesn't mean there has a better performance during the competition including mental factors (Michailov, Mladenov, \& Schoffl, 2009). 


\section{Conclusions}

Based on the research findings, it is suggested that the further research and insight into the handgrip strength for Malaysia's climbers to fully understand the performance determining factors in climbing. This is also showed that climbing performance can be explained by the variance of training. There is a tendency among climbers to share certain anthropometric characteristics, they are necessarily required to attain different on handgrip strength performance. The information gathers from the assessment can help the coach to plan and develop physical training that is more suitable and relevant for the Malaysia's climbers.

\section{Corresponding Author}

Borhannudin Abdullah is senior lecture at the Faculty of Educational Studies, Universiti Putra Malaysia, 43400 UPM Serdang, Selangor Darul Ehsan, Malaysia.

Email: borhannudin@upm.edu.my

\section{References}

Balas, J., Pecha, O., Martin, A. J., \& Cochrane, D. (2011). Hand-arm Strength and Endurance as Predictors of Climbing Performance. Journal of Sport Science, 1-10.

Bertuzzi, R., Pires, F. O., Lima-Silva, A., Gagliard, J. F. L., \& De-Oliveira, F. R. (2011). Performance Determining Factors in Indoor Climbing. Journal of Sports Medical, 17 (2).

Bohannon, R. W. (2008). Hand-Grip Dynamometry Predicts Future Outcomes in Aging Adults. Journal of Geriatric Physical Therapy, 31, 1-08.

Bourne, R., Halaki, M., Vanwanseele, B., \& Clarke, J. (2011). Measuring Lifting Forces in Rock Climbing: Effect of Hold and Fingertip Structure. Journal of Human Kinetics, 27 (1), 40-46.

Fleming, R. K., \& Horst, E. J. (2010). Behavior Analysis and Sport Climbing. Journal of Behavioral Health and Medicine, 1:143-154.

Gajewski, J., \& Jarosiewicz, B. (2008). Post-Exercise Decrease in Handgrip Force Following A Single Training Session In Male and Female Climbers. Journal of Sport, 9 (2), 121-123.

Gurer, G., \& Yildiz, M. E. (2015). Investigation of Sport Rock Climber's Handgrip Strength. Journal of Biology of Exercise, 11 (2).

Koley, S., \& Singh, A. P. (2010). Effect of Hand Dominance in Grip Strength in Collegite Population of Amritsar, Punjab, India. Journal of Anthropologist. 12 (1), 13-16.

Marrison, A. B., \& Schoffl, V. R. (2007). Review of the Physiological Responses to Rock Climbing in Young Climbers. Journal of Sports Medical.

Michailov, M. L., Mladenov, L. V., \& Schoffl, V. R. (2009). Anthropometric and Strength Characteristics of World-Class Boulderers. Journal of Medical Sport, 13 (4): 231-238.

Nick, D., Dickson, T., Fryer, S., \& Ellis, G. (2011). Self-Reported Ability Assessment in Rock Climbing. Journal of Sports Sciences, 29(8): 851-858.

Peter, L. (2004). Rock climbing: Essential skills and techniques. Capel Curig, UK: Mountain Leader Training UK.

PnanaCkova, M., Balas, J., Bunc. V., \& Giles, D. (2015). Physiological Demands of Indoor Wall Climbing In Children. Journal of Sports Technology. 
Quaine, F., \& Vigouroux, L. (2004). Maximal Resultant Four Fingertip Force and Fatigue of the Extrinsic Muscles of the Hand in Different Sport Climbing Finger Grips. International Journal of Sports Medicine, 25, 634_637.

Ryepko, O. A. (2013). Features and Functionallity of Speed and Power Capabilities of Elite Climbers and Various Types of Rock Climbing. Journal of Physical Education, 6: 60-65.

Watts, P. B. (2004). Physiology of difficult rock climbing. Journal of Applied Physiology, 91(4): 361372 